\title{
O QUE PRECISAMOS SABER SOBRE O CENSO PARA PODER FALAR SOBRE SEUS RESULTADOS? UM DESAFIO PARA NOVOS PROJETOS DE PESQUISA
}

Cecilia L. Mariz ${ }^{1}$

Considero bastante feliz e oportuna a decisão dos editores dos Debates do NER de escolher o artigo de Clara Mafra, Números e Narrativas, para ser comentado nessa edição da revista. Os dados sobre o perfil social e os percentuais das diferentes religiōes no Brasil apresentados pelo censo de 2010, divulgados no ano passado (2012), têm inspirado interpretaçôes distintas e por vezes conflitantes. As reflexões de Clara neste seu texto, que julgo muito rico e intelectualmente estimulante, ajudam a melhor entender o que está por trás dessas divergências de interpretações. Ajudam também a pensar sobre os problemas que ocorreram na interpretação dos dados sobre religião das duas últimas versões da Pesquisa de Orçamento Familiar (POF), 2003 e 2009.

Inicialmente, a autora nos lembra que números nunca falam sozinhos. Embora no senso comum se diga "os números não mentem”, sabemos que o que eles dizem depende da forma como foram obtidos. Os números dependem da metodologia utilizada para a coleta dos dados e também dos critérios adotados para criação das categorias que serão a base da análise estatística. Portanto, o texto mostra como alguns problemas e dificuldades para entender o que dizem os números podem ser minoradas ao se ter mais clareza sobre o que a autora chama de tecnologia de produção do números do censo, e acrescento aqui também a POF especialmente de 2003 e 2009, cuja metodologia também não é muito conhecida. Com efeito, aquilo que podemos depreender dos números será afetado pelo quanto sabemos sobre como esses números foram obtidos, ou seja, sobre a metodologia de pesquisa adotada. As narrativas podem variar ao se conhecer os problemas que foram enfrentados nessa coleta de dados, como foram treinados os

1 Doutora em Sociologia e professora da Universidade do Estado do Rio de Janeiro. E-mail: cecilia.mariz@pq.cnpq.br

Debates do NER, Porto Alegre, Ano I4, N. 24, P. 39-58, Jul./Dez. 2013 
recenseadores, como as categorias que agrupam os dados foram definidas e o que querem dizer.

Como falei acima, o texto em tela é muito rico, por isso meus comentários não vão abranger todos os pontos levantados pela autora. Irei me concentrar em apenas dois. O primeiro, que já adiantei acima, trata da necessidade de ampliar nosso conhecimento sobre a metodologia de pesquisa do IBGE, seja no censo, no POF ou em outra pesquisa cujos dados vamos utilizar. O segundo ponto, relacionado ao primeiro, é como esse desconhecimento tem afetado as interpretaçôes, especialmente no censo de 2010, sobre o que tem ocorrido no campo evangélico e também na questão sobre os sem religiāo. Além de tentar complementar alguns pontos discutidos no texto de Clara, nesse meu comentário tento mostrar que seu texto sugere um novo filão de pesquisa. Aponta para um novo campo de estudo quando estimula a reflexão metodológica e destaca o pouco que se sabe acerca de como tem sido elaborado e reelaborado esse rico banco de dados sobre religião no Brasil , cuja série histórica remonta a mais de um século. Apesar de lamentar o fato de haver apenas uma única questão sobre religião, Clara destaca o privilégio que o Brasil tem em relação a vários países cujos censos nada perguntam sobre esse tema.

\section{SOBRE A METODOLOGIA DO CENSO}

Em seu artigo, Clara Mafra elogia o trabalho do IBGE, a longevidade de seus dados e a sofisticação de sua metodologia de coleta de dados no quesito religião, que considera muito avançada. O IBGE não adota uma grade já predefinida de opção religiosa para o recenseado escolher. $\mathrm{O}$ recenseador é instruído para registrar a forma como o recenseado definirá a religião ou culto a que pertence. Essa metodologia sem dúvida tem vantagens e benefícios em termos de obtenção de novos dados em um campo dinâmico como o religioso brasileiro. A autora comenta que essa é uma metodologia mais avançada do que as metodologias geralmente adotadas por outros órgãos de pesquisa que levantam dados sobre religião, tanto no Brasil como no exterior, mas realmente é uma forma de fazer pesquisa que exige amplo trabalho poste- 
rior à coleta de dados. Também pode gerar alguns problemas. Para superar as dificuldades de categorização e análise desses dados coletados, o IBGE, desde o censo de 1991, tem buscado parcerias com órgãos especializados em pesquisa de religião, e seu parceiro nesses três últimos censos tem sido o Instituto de Estudo da Religião (ISER) do Rio de Janeiro, como já tem sido conhecido e comentado pela academia (Camurça, 2006; Mafra, 2004).

Nem todos os pesquisadores da religião no Brasil, e muito menos no exterior, tinham clareza em sua análise do censo de 2000, e também em 2010, dessa forma aberta de coleta de dados. Realmente, entende-se bem esse desconhecimento, porque essa metodologia tem sido relativamente pouco divulgada. Podemos observar esse desconhecimento em alguns comentários, como no de José Guilherme Magnani (2006) sobre o censo de 2000, e também nos de Péricles Andrade e Jonatas Menezes (2013). Evidentemente, não os critico de forma alguma. Confesso que também somente soube mais dessa forma de coleta de dados por estar no Rio de Janeiro, em contato cotidiano com a própria Clara, que assessorou, como representante do ISER, o IBGE na categorização do censo de 2000. No entanto, nem mesmo assim teria tido muita clareza de como isso se dava se não tivesse conversado pessoalmente com ela, lido seu texto anterior (Mafra, 2004) e conversado com técnicos do IBGE, como Maria Goreth Santos, e outros que assessoram o IBGE pelo ISER, como Marcelo Camurça junto ao censo de 1991 (assessoria que ocorreu, como me esclareceu, em 1996).

Portanto, foi muito importante que Marcelo Camurça (2006) e Clara Mafra (2004) tenham publicado sobre essas suas experiências. $\mathrm{O}$ artigo atual de Clara se distingue muito do anterior, acima citado. No presente texto, ela chama bastante atenção aos aspectos positivos do trabalho do IBGE e do censo. Não há crítica negativa. Seu texto atual se afasta do anterior sobre o tema, cujo tom teria sensibilizado negativamente a equipe do IBGE. Entre as qualidades que sublinha, está a capacidade do censo brasileiro de ter conseguido se manter por tanto tempo e assim apresentar uma série histórica bastante longa. A autora elogia assim a longevidade dessa coleta de dados, que tem se realizado a praticamente cada década e que já dura agora por mais de um século. Entendo que ao destacar a necessidade de se ter mais conhecimentos sobre a produção

Debates do NER, Porto Alegre, Ano I4, N. 24, P. 39-58, Jul./Dez. 2013 
de dados, a autora queira estimular e propor que sejam elaborados mais textos sobre a metodologia do censo e também que sejam realizadas pesquisas sobre perfil e prática da coleta de dados pelos recenseadores em diferentes partes do país. Essa necessidade também tem sido sentida por Maria Goreth Santos que, como mencionei acima, é uma socióloga que trabalha no IBGE e que tem participado em muitos debates com os diversos pesquisadores que analisam o censo. Maria Goreth já está procurando levantar dados dentro do próprio IBGE sobre todo o processo de pesquisa e já se organiza para apresentar seus primeiros resultados nos próximos congressos de 2013, se tudo der certo. A seu exemplo, outros membros do próprio IBGE ou pesquisadores de fora, mas com apoio desse instituto, poderiam propor estudos diversos para conhecer mais sobre vários pontos da forma como têm sido feitos os diversos censos e levantamentos de dados pelo IBGE.

A autora comenta sobre a escassez de informações empíricas a respeito de como é feito o censo. Esse comentário nos sugere a possibilidade de realizar pesquisas com os recenseadores para conhecer um pouco de seu perfil e também saber como se deu o cotidiano da coleta desses dados, quais são os problemas e limites sentidos pelos recenseadores em diferentes partes do país e como eles interpretaram as instruções dadas durante o treinamento. Houve divergências nas instruções das diversas partes do país? Uma questão importante para comparar a série histórica é ter clareza sobre as mudanças de 2000 para 2010. O próprio instrumento de coleta de dados com tecnologia bem mais avançada pode ter afetado de alguma forma os dados? Que correções ou distorçôes essa nova tecnologia previne ou aumenta nos riscos? Sabemos que todas as opções metodológicas e técnicas implicam custos e benefícios e que evidentemente se opta por menos custos, mas isso não quer dizer que, com efeito, se eliminem os riscos e problemas, apenas aparecem novos. A pergunta principal no caso seria: quais seriam esses novos riscos e como eles vão afetar nossas análises. Um deles, como veremos adiante, é criar categorias que se sobrepõem. Isso problematiza muito a análise da quantidade de membros de cada igreja. Alguém que se diz evangélico pode ser da Igreja Universal.

$\mathrm{O}$ se definir como evangélico não significa negar o pertencimento a uma denominação, já que a pergunta era apenas "qual sua religião e/ou 
culto?”. O recenseador foi instruído para não refrasear a questão, não dar mais esclarecimentos e não solicitar mais detalhes ou informações diante de qualquer resposta dos recenseados. Mas será que todos fizeram isso mesmo? Será que os dados foram afetados por alguma variação na forma como os dados foram coletados?

Assim, uma linha de pesquisa sobre a metodologia do censo poderia se constituir de pesquisas empíricas, qualitativas ou quantitativas com amostras, em diversas partes do país, para se descobrir como se deram os treinamentos dos recenseadores em cada centro de pesquisa ou, ao menos, em centros de pesquisa onde os dados parecem muito divergentes, como no caso que citarei adiante de Nova Ibiá, na Bahia. Uma outra pesquisa que poderia ser feita com amostra de recenseadores e/ou supervisores seria sobre problemas enfrentados na obtenção de dados e na forma como se entendia a pergunta. Será que os recenseadores se contiveram e perguntaram apenas a questão como proposta pelo censo? Será que o novo instrumento eletrônico para coleta, que permitiu mais rapidez, não afetou de alguma forma essa coleta? Como isso afetaria a comparação entre dados de 2000 e 2010 e em que pontos relativizariam as interpretações da série histórica, que nos é tão útil e inspira tanto debate? Nesse sentido, poderia se constituir uma outra linha de pesquisa com um caráter mais histórico e com foco na forma como tem evoluído a metodologia do censo sobre religião através das décadas.

Seria importante saber quando foi adotada pela primeira vez a pergunta do tipo aberta para identificar o pertencimento religioso. Teria sido em 1991, quando pela primeira vez o IBGE sentiu necessidade de assessoria do ISER para organizar os dados obtidos, criando categorias que sumarizassem as milhares de respostas de religióes diversas que surgiram, como lembra bem Camurça (2006)? Em que medida a adoção dessa nova metodologia pode ter afetado a série histórica? Essas questôes não significam que de alguma forma se queira invalidar os dados já obtidos que, tudo indica, refletem algum aspecto importante da realidade, mas sim evitar extrapolações indevidas e permitir que os dados sejam mais bem avaliados e interpretados.

Sobre a questão aberta há muito que se refletir. Não se pode negar o valor de tal metodologia, mas é preciso reconhecer seus riscos e custos. Sua 
adoção deve ter sido resultado de uma avalição em que os benefícios suplantavam os custos. Graças a esse tipo de metodologia, é possível identificar e contabilizar novas religiōes. No entanto, se não se pergunta a qual igreja ou denominação se pertence, o censo não consegue captar a dinâmica do campo evangélico e o surgimento constante de novas igrejas. Segundo o Censo Institucional Evangélico (produzido pelo ISER (1992), era oficialmente registrada uma igreja por cada dia útil (5 por semana) no biênio 1991-92, na Região Metropolitana do Rio de Janeiro.

Portanto, a grande vantagem dessa metodologia era poder conseguir captar religiōes e novas igrejas. Mas se de fato o recenseador não pode perguntar qual a igreja, essa vantagem se perde. Nesse sentido, Clara Mafra tem razão. Ao menos mais uma pergunta poderia ser feita. Talvez mais um item podia ser acrescentado à pergunta tradicionalmente feita. Ao invés de "Qual sua religião e/ou culto?", poderia ser proposta a pergunta "Qual sua religião, culto e igreja?”. Além disso, o recenseador poderia ser instruído a ver se o entrevistado prefere mesmo omitir o nome de sua igreja ou se omitiu porque a pergunta não foi feita.

Clara Mafra insiste que, embora o conhecimento da tecnologia de produção de dados ajude a resolver algumas controvérsias de interpretação, nem todas poderão ser solucionadas, e sublinha que o IBGE deveria incluir mais uma questão sobre religião. Reforçando seu argumento da relevância de se investir mais no conhecimento da religião, colocando mais uma pergunta, a autora lembra a importância que essa única questão do censo sobre religião tem tido para a academia, para os grupos religiosos e, enfim, para a mídia e a sociedade em geral. Sublinha o ponto destacado por Renata Menezes em entrevista dada à IHU On-Line sobre a grande expectativa quanto à divulgação desses dados do IBGE, por parte não apenas dos que estudam religião, mas dos próprios religiosos, dos setores políticos e da população em geral, que se reflete na busca da mídia por reportagens sobre o tema.

Sem dúvida, não apenas acadêmicos mas também líderes religiosos sentem a necessidade de saber como são computados os fiéis que aderem a sua igreja ou movimento de fé. Também para eles o conhecimento dessa tecnologia é fundamental. Na medida em que souberam que não havia uma 
grade de opções fechadas, líderes católicos e também espíritas procuraram ensinar o que seus fiéis deviam responder ao censo. Da mesma forma que houve um movimento por parte dos grupos afrodescendentes para que estes se identificassem como negros.

Essa preocupação de líderes religiosos em divulgar a metodologia do censo e ensinar os fiéis a nomear corretamente sua religião foi comentada por Sílvia Fernandes, professora da UFRRJ e especial conhecedora do campo católico no Rio de Janeiro. Ela registrou que nessa diocese os padres foram instruídos para lembrar aos fiéis nas missas dominicais que deveriam se identificar no censo como membros da Igreja Católica Apostólica Romana. A categoria catolicismo carismático não existe de fato.

Também foi possível observar processo similar entre os espíritas kardecistas, que fizeram campanha através de seus sites e no boca a boca sobre a necessidade de identificarem corretamente sua fé. Havia um problema para os espíritas: os umbandistas também se consideram espíritas, embora os espíritas não os considerem assim. Apesar disso, o recenseador não teria como diferenciar.

Líderes religiosos, portanto, estavam sabendo que os fiéis não se encontrariam com opções fechadas e tinham clareza de que a forma como se autoidentificassem poderia ser mal interpretada. No entanto, nem sempre estavam a par de todos os detalhes.

Assim, as lideranças do Espiritismo Kardecista, por intermédio de seus sites, chamavam atenção para a importância de como deviam se identificar para que sua religião fosse corretamente identificada pelo IBGE. À época da aplicação dos questionários do censo, houve recomendaçôes aos espíritas que revelaram uma falta de informação. Essa primeira recomendação, divulgada em 02 de agosto de 2010, logo foi retificada por uma segunda recomendação. Após novos contatos com o IBGE, foi enviada logo no dia seguinte (03 de agosto) a recomendação retificadora. A primeira recomendação, encontrada no site a Voz do Espiritismo ${ }^{2}$, tinha espaço bem destacado para

2 Essa era uma colaboração de Pedro Bonilha, de Jales, São Paulo, ao site $A$ Voz do Espiritismo, que pode ser encontrado no endereço <http://www.avozdoespiritismo.com.br/ censo-2010-espirita-muita-atencao-ao-responder-sobre-religiao-responda-kardecistaveja-por-.que>. Acesso em: 14 maio 2013.

Debates do NER, Porto Alegre, ANo I4, N. 24, P. 39-58, JUl./DeZ. 2013 
chamar a atenção do leitor, como se nota a seguir: "Censo 2010: Espirita, muita atenção ao responder sobre religião. Responda Kardecista. Veja por que. REPASSE PARA TODOS OS SEUS AMIGOS 'KARDECISTAS”.

$\mathrm{O}$ site explicava que dois tipos de questionário seriam aplicados pelo censo: um mais curto seria aplicado a todas as residências, e outro mais longo e detalhado seria aplicado apenas a uma amostra das residências. $\mathrm{O}$ site continua:

Neste último constará uma pergunta, cuja resposta é de fundamental importância para nós Espíritas. A pergunta é: Qual a sua religião? Claro, que muitos de nós responderemos: ESPIRITA. Infelizmente, se respondermos assim, seremos cadastrados como SEM OPÇÃO RELIGIOSA. É que para o IBGE, o termo ESPIRITISMO é considerado genérico, ou seja, pode se referir a toda religião, culto ou seita que envolva questôes do campo da mediunidade. Nós sabemos que muitas pessoas adeptas da Umbanda, por exemplo, se consideram Espíritas umbandistas e o mesmo equivoco ocorre com outras denominações como espírita esotérico, espírita de mesa, etc. O fato é que ao invés de respondermos ESPÍRITAS, temos que responder KARDECISTAS, pois é esta a denominação dada pelo IBGE ao que para nós é simplesmente ESPÍRITA.

O colaborador do site segue alertando: "CUIDADO: Ao responder o questionamento do recenseador não digam ESPÍRITA nem esperem o recenseador perguntar mais detalhes, pois ele não perguntará. A pergunta é direta e a resposta deverá ser uma só."

Nessa recomendação se enfatiza a urgência de que isso seja esclarecido a todos, pois se não o fizessem os dados sobre a quantidade de espíritas somente seriam revistos no próximo censo, em 10 anos. Por esse motivo, solicita-se ao leitor, em letras destacadas em negrito: "Repasse em suas listas de email; envie para jornais, revistas, rádios, TV's e divulgue nas casas espiritas".

No entanto, os dirigentes do movimento espírita se deram conta do engano da informação e da forma como foi divulgada, e no dia seguinte a retificação é postada, como podemos ver no site espírita $O$ semeador:

3 Embora o texto seja assinado por João Pinto Rabelo, identificado como Diretor de Comunicação Social da FEB (Federação Espírita Brasileira), o site informa: "colaboração de cursino 
Por orientação do presidente Nestor João Masotti, ausente do País em viagem a Nova York, em evento que homenageia Chico Xavier, na sede da ONU, RETIFICAMOS a informação transmitida no dia 2 de agosto, a respeito do Censo demográfico 2010, promovido pelo IBGE. Diante dos novos esclarecimentos, obtidos em consulta direta ao Órgão, pedimos considerar que, aos pesquisadores do IBGE, poderão ser respondidas as alternativas ligadas ao código 610 , todas relacionadas a uma mesma opção: Espírita. A exemplo, poderão ser respondidas as opçōes Allan Kardec, Cardecismo, Cardecista, Kardecismo, Kardecista, Centro Espirita, Doutrina Espirita, Federação Espírita Brasileira e Espiritismo, entre outras, como estão relacionadas no documento do IBGE que anexamos.

\section{QUEM SÃO OS QUE SE ENCONTRAM NA CATEGORIA} "EVANGÉLICA NÃO DETERMINADA" NO CENSO DE 2010?

No censo de 2000, encontra-se dentro da categoria mais ampla referente à religião evangélica uma subcategoria chamada de sem vínculo institucional. No entanto, durante o processo de análise dos dados do censo de 2010, os técnicos e assessores do IBGE, que conheciam como esses dados foram coletados e agrupados, reviram essa forma de nomear a mesma categoria. Chegaram à conclusão de que nomear essa subcategoria como sem vínculo estava errado, pois em suas respostas os entrevistados, que aí estavam contabilizados, tinham dito apenas que sua religião era evangélica e nada mencionavam sobre ter ou não vínculo institucional, nem ter ou não participação em alguma igreja. Como não foram perguntados a que igreja eles pertenciam, podiam ter achado que não precisariam ou não deveriam informar a sua denominação. Por isso, no censo de 2010, a categoria passou a ser chamada de evangélico sem declaração de denominação. Essa nova terminologia é bem mais precisa e descreve melhor o que o dado significa: evangélicos que omitiram sua pertença denominacional. Sobre o motivo dessa omissão, nada se sabe e nada se pode declarar. No censo de 2010, essa categoria chega a 9.218.129 pessoas, correspondendo a $21,8 \%$ do total de evangélicos. Um percentual mais elevado do que o da categoria evangélicos de missão.

em 03/08/2010”. Disponível em: <http://ceosemeador.wordpress.com/2010/08/03/ recomendacao-aos-espiritas-no-censo-2010/>. Acesso em: 14 maio 2013.

Debates do NER, Porto Alegre, Ano I4, N. 24, P. 39-58, JUl./Dez. 2013 
Como a pergunta era apenas qual sua "religião e/ou culto", pode se pensar que muitos preferiram responder apenas a religião por economia de tempo, por privacidade ou por tantos outros motivos, e não necessariamente por não ter nenhuma prática e denominação religiosa. Dessa forma, entre esses podem estar muitos evangélicos praticantes ligados a qualquer igreja, que não vamos saber quais, e pode haver os sem igreja também, mas não temos informações sobre isso no censo. Portanto, não se pode supor que essa categoria exclua evangélicos que têm denominação. São assim categorias que se sobrepõem e não excludentes.

Em pesquisas quantitativas, o recomendado é a elaboração de categorias excludentes, para que as análises estatísticas possam ser coerentes. Como foi adotada no quesito religião essa questão aberta e que não pode ser complementada com pedidos de esclarecimentos, se torna quase impossível construir tais categorias excludentes. $\mathrm{O}$ recenseador devia registrar o que o pesquisado falava, como já foi dito. Mas o pesquisado não imaginava, por exemplo, que podia declarar pertencer a mais de uma religião (essa informação foi contabilizada e considerada sub-representada por quem conhece o campo religioso brasileiro). Também poderia, se quisesse, declarar que pertencia a mais de uma igreja, o recenseador deveria anotar qualquer coisa. Veremos também que muitos entrevistados não sabiam que poderiam dizer que eram agnósticos ou ateus quando respondessem que não tinham religião.

No entanto, o problema já tinha sido criado com essa forma imprecisa de se referir àquela categoria no censo de 2000, e especialmente nos anos seguintes, em que foi divulgada a chamada Pesquisa de Orçamento Familiar (POF) de 2003 e de 2009. A análise desse censo e também dessas POF sofre por falta de conhecimento da metodologia de pesquisa e, como mencionei acima, especialmente por ignorar como as categorias de análise foram construídas e também como os dados foram coletados. Isso tem causado no estudo do campo evangélico muito mais problemas do que no estudo de outras religiōes. A partir de então, se iniciam muitos debates sobre o significado da crescente categoria de evangélico sem vinculo. Parecia que estava crescendo intensamente um tipo de evangélico chamado por Ricardo Mariano de genérico, aquele que não tem denominação alguma. Esse grupo

Debates do NER, Porto Alegre, ANo I4, N. 24, P. 39-58, JUl./Dez. 2013 
pode até estar crescendo, mas o censo não tem condições de falar sobre isso. Não são os dados do censo nem da POF que vão nos falar sobre isso.

A metodologia empregada nas POF, no quesito religião, são ainda menos discutidas e mais desconhecidas por aqueles da academia ou da mídia que debatem sobre os números que elas produzem do que as dos censos. Em que se assemelham ou se distinguem essas metodologias? Em que medida seus dados podem ser comparados? Quais os limites e alcances dos dados sobre religião que têm sido analisados por essas pesquisas realizadas em 2003 e 2009?

Apesar de tanto desconhecimento sobre o que esses dados significam, muito se tem escrito a partir deles, tanto pela academia (dentre esses, destacamos os trabalhos de Marcelo Neri, da FGV do Rio de Janeiro, a ser comentado adiante) como pela mídia e pelas lideranças religiosas. No site do Observatório Bíblico, tal como foi observado em blog religioso, se afirma: "Entre 2003 e 2009, por exemplo, a proporção de evangélicos sem vínculo institucional subiu de $4 \%$ para $14 \%$, conforme Pesquisa de Orçamentos Familiares do IBGE, reportada pelo blog Observatório Bíblico ${ }^{4}$."

Várias narrativas controversas sobre o campo evangélico surgiram por essa ignorância do que realmente tratam os dados do censo de 2010. A enorme quantidade de evangélicos que não revelaram sua igreja levou a uma queda proporcional e absoluta nos membros de várias igrejas. Proporcionalmente, o pentecostalismo cai entre evangélicos, embora continue maioria. Os evangélicos que não declararam denominação superam os que se declaram de igrejas históricas em 2010, como já foi dito. Evidentemente mal interpretando a categoria citada, considerando-a excludente em relação às demais, foram elaboradas muitas análises que concluem pela queda proporcional do crescimento pentecostal e a queda absoluta de várias igrejas evangélicas históricas e também pentecostais.

Em seu texto em pauta, Clara está bem atenta a esse problema e destaca o caso da Igreja Universal do Reino de Deus, cujos números absolutos caíram

4 SILVA, Airton José (airtonjo). "Crer sem pertencer a uma igreja”. Observatório Bíblico: Blog sobre estudos acadêmicos da Bíblia Associado à Ayrton's Biblical Page. 2011. Disponível em: <http://blog.airtonjo.com/2011/08/crer-sem-pertencer-uma-igreja. html>. Acesso em: 10 maio 2013.

Debates do NER, Porto Alegre, Ano I4, N. 24, P. 39-58, Jul./Dez. 2013 
entre 2000 e 2010. "Não estariam muitos dos membros da IURD se identificando apenas como evangélicos?", ela se pergunta. Apesar de reconhecer que a IURD pode ter sofrido perda real com a saída de Valdomiro Santiago e a criação da Igreja Mundial do Poder de Deus, destaca que os dados do censo são incapazes de mostrar isso por causa da quantidade de evangélicos que omitiram sua denominação. Meu comentário segue a linha do argumento da autora, mas pensando também no caso das igrejas históricas, no censo definidas como evangélicos de missão. Também muitas dessas caíram em termos absolutos. Estariam de fato perdendo tantos fiéis? É de se estranhar porque pesquisas qualitativas apontam para um reavivamento em igrejas históricas, com abertura para um estilo carismático, como mostra o estudo de Carlos Henrique de Souza (2013), realizado na Catedral Metodista do Catete, no Rio de Janeiro.

Em suas análises baseadas nas duas POF 2003 e 2009, Neri concluía que em 2003 o catolicismo tinha quase se estabilizado e que a perda de seus fiéis estava mais lenta. Já baseado na de 2009, a análise de Neri (2011) sublinhava que os católicos voltaram a perder fiéis na mesma proporção anterior, mas que as igrejas pentecostais tinham seu crescimento estabilizado e que as tradicionais (de missão ou históricas) passavam a crescer mais do que as pentecostais! Conhecer mais sobre a metodologia tanto das POF como do censo é fundamental para que esses dados sejam adequadamente entendidos e padeçam menos de problemas de interpretação, tanto em sua análise quanto em sua comparação com o censo.

Essa análise de Neri está também disponível on-line em entrevista ${ }^{5}$ concedida em 2011, à época do lançamento da análise dos dados sobre religião da POF de 2009. Aí, o pesquisador comenta que as igrejas tradicionais passam a crescer. Esse resultado, ao menos o do crescimento das igrejas tradicionais, era coerente com o que se observava quando comparávamos os dados do censo de 1991 e 2000. Também tinha certa plausibilidade por ser apoiado em observações do que ocorria em igrejas históricas que

5 Esta entrevista - Lançamento da pesquisa: Novo Mapa das Religiōes-Marcelo Neri (FGV/ CPS) está disponível em vídeo está disponível em vídeo no endereço: < http://cps.fgv. br/video_ren>. Acesso em: 19 maio 2013.

Debates do NER, Porto Alegre, Ano I4, N. 24, P. 39-58, JUl./Dez. 2013 
estavam aderindo a um tipo mais moderado de pentecostalismo, que tem sido identificado como carismatismo. O estudo de caso realizado por Carlos Henrique Souza (2013), já citado acima, na Catedral Metodista do Rio de Janeiro, observa que pastores e membros leigos comentam como aumentou a presença de fiéis em cultos mais carismáticos ou pentecostais. Dessa forma, essa pesquisa na igreja metodista sugere que pode haver também os que não declaram a denominação a que pertencem como a de membros de igrejas históricas. Essas igrejas podem estar até crescendo, como cresceram entre 1991 e 2000, como observaram Pierucci e Mariano (2010).

A categoria evangélicos sem declarar vínculos, dessa forma, pode incluir evangélicos de qualquer denominação, como já foi dito, e não é excludente em relação às demais categorias de evangélicos. Então como saber quem seriam esses evangélicos que não declaram sua igreja? Não podemos saber ao certo sem novas perguntas e sem novas pesquisas, como sugere Clara. No entanto, enquanto não se têm mais dados, tal como a autora e eu fizemos, outros pesquisadores, conscientes também desse problema, têm proposto hipóteses diferentes.

Uma dessas é a levantada por Péricles Andrade e Jonatas Menezes (2013, p.10-11), que fazem a mesma pergunta sobre quem são os que não revelaram sua denominação:

Seriam fiéis omitindo seu pertencimento por estar vinculados a grupos estigmatizados (Universal do Reino de Deus ou Mundial do Poder de Deus), à semelhança do que ocorria nas décadas passadas com os religiosos da Umbanda e do Candomblé? Ou seriam fiéis vinculados aos grupos dissidentes menores e que se espalham por todos os recantos do Brasil?

Esses autores descartam a primeira opção porque consideram que há atualmente uma abertura maior para os grupos religiosos mais diversos, e que tais igrejas acima não seriam assim tão estigmatizadas. Argumentam pela segunda opção, afirmando:

[...] muito provavelmente esses declarados sem denominação refletem o processo de fragmentação no interior do universo pentecostal e/ou neopentecostal, no qual lideranças insatisfeitas política ou doutrinariamente rompem com seu grupo de origem,

Debates do NER, Porto Alegre, Ano I4, N. 24, P. 39-58, JUl./DeZ. 2013 
formando uma nova denominação, quase sempre de uma igreja só, que não aparecerá nos dados do IBGE (Andrade; Menezes, 2013, p.11).

No entanto, essas pequenas e mesmo microigrejas poderiam ser categorizadas como outras denominaçôes (há essa categoria), se os fiéis declararem sua filiação a elas. Na medida em que a metodologia do IBGE é feita justamente para anotar o nome de todas as religiões, opções de fé, igrejas e denominações tais como declaradas pelo fiel, não procede o argumento de que por serem de criação recente e pequenas, essas microigrejas não estariam no banco de dados do IBGE. Essa metodologia, como Clara Mafra chama atenção, é bastante sofisticada e foi adotada justamente para dar conta desse processo de fragmentação do campo religioso e de surgimento de novas igrejas e grupos de fé. $\mathrm{O}$ argumento faria sentido se o próprio fiel dessas novas e pequenas igrejas, por algum motivo, decidisse não declarar o nome delas. Por que o fiel dessas microigrejas deixaria de declarar seu nome? Os autores não apresentam esses possíveis motivos. Declarando sua denominação, passariam a estar no banco do IBGE e seriam contabilizadas como outras igrejas pentecostais. A hipótese de não constar no banco de dados, dessa forma, não procede, porque a resposta é aberta e não há grade fechada. Portanto, essas pequenas igrejas estão contabilizadas em outras igrejas pentecostais, categoria que unifica todas as pequenas igrejas e cuja contabilidade individual seria muito pouco significativa em termos estatísticos.

Pode-se também levantar a hipótese de que entre esses que não declararam sua denominação, estão alguns que participam de mais de uma igreja. Em sua dissertação de mestrado, baseada em um estudo qualitativo sobre microigrejas fundadas por mulheres em Nova Iguaçu, Baixada Fluminense, no Rio de Janeiro, Janine Targino da Silva (2010) observa que os fiéis dessas igrejas vão a mais de uma, circulam entre as igrejas. Talvez por isso possam preferir dizer que são evangélicos apenas. Talvez isso ocorra também nas igrejas mencionadas por Andrade e Menezes (2013), que parecem ser similares as analisadas por Janine Targino. $\mathrm{O}$ fato da frequência simultânea em denominações diversas já foi observado antes mesmo, em grandes denominações pentecostais (Mariz, Machado, 1994; Machado, 1996). Essas práticas 
simultâneas e reforço de uma identidade evangélica única, seja pela política irmão vota em irmão, destacada por Freston (1993), ou por eventos como a "Marcha de Jesus", como já tinha apontado antes com Paulo Gracino (Mariz, Gracino Jr, 2013), podem contribuir para que o entrevistado não sinta necessidade de dizer o nome de sua igreja.

\section{O PROBLEMA DOS SEM RELIGIÃO}

O mesmo tipo de problema também reaparece na categoria sem religiāo. Os ateus e agnósticos contabilizados são apenas os que assim se definiram. Mas podemos supor que muitos não declararam isso porque a pergunta era "qual sua religiāo elou culto" e ateísmo ou agnosticismo não são religiōes nem cultos. Alguns podem ter querido marcar posição, mas muitos podem ter evitado aprofundar o tema e responder apenas o que foi perguntado. Não quero argumentar que os sem religião sejam em grande parte ateus/ agnósticos, tenho até outras hipóteses sobre isso, que comentarei a seguir, mas argumento apenas que certamente os percentuais de ateus e agnósticos podem estar subestimados.

É interessante atentar para o relato que tive por meio de Maria Goreth Santos, a quem já me referi antes, sobre o protesto do presidente de uma associação nacional de ateus junto ao IBGE. Protestou, segundo ela, por não saber que o IBGE contabilizava o número de ateus, e então ele apenas teria dito ao recenseador que era sem religião, e quando soube posteriormente que havia possibilidade de ter sido contabilizado como ateu e não o foi, ficou indignado.

A categoria ateu, da mesma forma que agnóstico, foi criada a partir de declaraçôes espontâneas, e não a partir de uma pergunta específica. Já que, como foi já dito, os recenseadores, pelo menos no Rio de Janeiro, eram instruídos a não oferecer nenhuma grade de opções de resposta nem fazer uma segunda pergunta. No entanto, já escutei relatos de pessoas que disseram que no censo de 2000, diante de sua resposta de que não tinham religião a uma recenseadora, esta fez mais questôes do tipo: "A senhora não acredita em Deus? Posso colocar ateia?", e que a respondente teria iniciado uma conversa sobre ter

Debates do NER, Porto Alegre, Ano I4, N. 24, P. 39-58, JUl./Dez. 2013 
dúvidas e a recenseadora então sugeriu "posso colocar como agnóstica?”. Assim, a entrevistada ficou sabendo que podia ser contabilizada como agnóstica.

A partir desse relato, perguntaria ao IBGE se no treinamento dos recenseadores de 2000 teria sido enfatizada também a importância de se fazer apenas uma pergunta. Esse comportamento da recenseadora pode ter ocorrido em outros locais e também no censo de 2010. Teriam todos os recenseadores em 2010 obedecido as normas ou teriam alguns tido a tentação de perguntar algo mais enquanto outros se davam por satisfeitos com uma primeira resposta simples? Essas são questōes que somente podem ser respondidas em pesquisas que esse texto de Clara Mafra estimula. Como não pode ser garantido que outros recenseadores não tenham agido como a acima citada, a proposta de Clara Mafra de que o IBGE acrescente mais uma pergunta sobre religião pode não ser tão custosa, e pode já estar sendo realizada de uma forma ou de outra devido à curiosidade e autonomia dos recenseadores.

Uma outra temática abordada no texto analisado é o significado do crescente número de sem religião em meios populares e também em áreas pouco industrializadas, e nesse sentido menos "modernas", como é o caso de estados rurais do norte do país, como Rondônia e Roraima. O que significa esse crescimento nos meios populares? Como explicar que o perfil de parte significativa dos sem religião é em vários aspectos muito semelhante aos dos pentecostais, em termos de regiões geográficas e também em termos de renda e instrução, diferindo mais em termos de idade (os sem religiāo são mais jovens)? Novamente, surge uma questão para pesquisas futuras. Os dados do censo não podem responder, mas hipóteses são levantadas.

É interessante aqui lembrar uma reportagem da $V e j a^{6}$, citada por Denise dos Santos Rodrigues (2009) em sua tese de doutorado sobre os sem religiāo. A reportagem discutia um dado completamente intrigante registrado no censo de 2000: um alto percentual de pessoas que se declararam sem religião em uma pequena cidade do interior da Bahia, Nova Ibiá. O repórter comenta:

6 PETRY, André. Como a fé resiste à descrença. Veja, 12 dez. 2007. Disponível em: <http://veja.abril.com.br/261207/p_070.shtml>. Acesso em: 10 maio 2013.

Debates do NER, Porto Alegre, ANo I4, N. 24, P. 39-58, JUl./Dez. 2013 
Há algo que não se encaixa. Em 1991, o censo do IBGE descobriu que havia $6,35 \%$ de pessoas sem religião na cidadezinha e que $83,35 \%$ da população dizia ser católica. Em 2000, no novo censo, a realidade havia virado de ponta-cabeça: $59,85 \%$ afirmavam não ter religião e apenas 16,02\% diziam-se católicos.

Após visitar a cidade e entrevistar pessoas, a reportagem da Veja quase não encontra pessoas que declaram não ter religião e conclui que "[...] a queda vertiginosa de $83,35 \%$ para $16,02 \%$ de católicos em nove anos é inexplicável." Uma explicação corrente na cidade, e que foi passada ao repórteres pelo padre local, era a de que se dizia que por serem os recenseadores que trabalharam na cidade naquele censo evangélicos, "[...] quando um católico dizia ser católico, mas não praticante, eles cravavam 'sem religiāo' por conta própria". Mas o próprio padre que forneceu essa resposta continuava explicando que foi o que "ouviu dizer", mas comentava "Não sei se é verdade".

Os dados do censo de 2010 nos levam a concluir que houve de fato algum problema na coleta dos dados em 2000. Ao contrário da tendência nacional, nesse município o número de pessoas que se declararam sem religiāo caiu para $17,22 \%$, e o de católicos subiu (de 16,02\% para 51,99\%). No entanto, 17,22\% de sem religião ainda está bem acima da média nacional $(8 \%)$. A reportagem não deixa de sugerir reflexão sobre um certo grau de independência e autonomia de recenseadores que podem não obedecer o treinamento tal como recebido, e também sobre a influência que o crescimento da cosmovisão evangélica, via principalmente o pentecostalismo, pode ter na camada popular do que significa ter religião. Depois de passar por igrejas evangélicas, talvez muitos tenham incorporado a concepção dessas igrejas de que ter religião é praticá-la de alguma forma. Em várias dessas igrejas, quem desvia pode ser desligado. Quem se identifica como de tal igreja tem que seguir várias normas, e é cobrado também pela sociedade mais ampla um tipo de comportamento. Outra explicação pode ser que quem assim respondeu estivesse querendo evitar tomar partido em debates sobre religião. No passado, quem quisesse evitar isso apenas precisaria se dizer católico, mas com o crescimento do pentecostalismo isso pode ter mudado. 
Embora não possamos verificar essas hipóteses com os dados do censo, observa-se nesses dados uma relação entre o crescimento pentecostal e o dos sem religiāo (ambos ocorrem em contextos sociais e geográficos similares). Essa relação aparece também nos dados analisados por Sílvia Fernandes (2008). Em seu artigo sobre os sem religião, baseado em dados de pesquisa do CERIS (Mobilidade Religiosa no Brasil, 2006), Silvia Fernandes (2008, p.36) observa que há percentualmente mais indivíduos que se declaram sem religião que indicaram que sua última religião foi evangélica $(44,5 \%)$, considerando históricos e pentecostais em conjunto, do que católicos. O percentual dos que disseram que sua última religião foi católica era um pouco menor, 42, 01\%, mas comparando ambos percentuais dessas religiōes com seus percentuais no total da população, essa diferença se torna significativa. Por outro lado, é importante notar que $60 \%$ dos sem religiāo, à época da pesquisa, declararam que já tinham sido católicos em algum momento de suas vidas. Comparando com o total da população católica e evangélica, fica evidente uma tendência de que os sem religião tenham vindo do mundo evangélico. Pessoas criadas católicas parecem ter passado por igrejas evangélicas antes de optar por ficar sem religião. Esses dados são coerentes com o fato de que, segundo o censo, se observa uma similaridade entre o perfil social dos sem religião e o dos evangélicos, e também para o fato de que cidades e estados com maior proporção de evangélicos são os que têm também maior proporção de sem religião.

Opções metodológicas, como tudo na vida, têm custos e benefícios. O benefício da questão em aberto para religião é permitir que se incluam novas religiōes. Mas tem desvantagens, especialmente quando a pessoa não sabe que ao perguntar "qual é a sua religião ou culto", o pesquisador quer saber e contabilizar igrejas. Esse tipo de pergunta aberta tem impedido a criação de categorias excludentes, e assim impedem também uma análise estatística adequada. Como falei no início do texto, considero que Clara Mafra contribui muito ao iniciar de forma ampla e criativa um debate sobre a metodologia do censo e estimular pesquisas sobre isso. Finalizo, chamado a atenção do IBGE, que talvez a questão a mais que Clara solicita esteja sendo feita de uma forma ou de outra por parte dos recenseadores. Portanto, não deve ser tão mais custoso incluí-la. Então, por que não o fazer?

Debates do NER, Porto Alegre, ANo I4, N. 24, P. 39-58, JUl./Dez. 2013 


\section{REFERENNCIAS}

ANDRADE, Péricles; MENEZES, Jonatas. Censo 2010: antigas questôes e novos desafios interpretativos à Sociologia da Religião. Cadernos do Tempo Presente, n. 10, 2013. Disponível em: <www.getempo.org>. Acesso em: 17 maio 2013.

CAMURÇA, Marcelo Ayres. A realidade das religióes no Brasil no Censo do IBGE - 2000. In: TEIXEIRA, Faustino; MENEZES, Renata (Orgs.). As religiōes no Brasil: continuidades e rupturas. Petrópolis: Vozes, 2006.

FERNANDES, Sílvia R. A. Sem religião e identidades religiosas. Interseções, ano 10 n. 1, p. 31-46, 2008.

FRESTON, Paul. Protestantes e Política no Brasil: Da Constituinte ao Impeachment. Tese (Doutorado em Ciências Sociais) - Universidade Estadual de Campinas, Campinas, 1993.

MACHADO, Maria das Dores C. Carismáticos e pentecostais: Adesão religiosa na esfera familiar. Campinas: Ed. Autores Associados, 1996.

MAFRA, Clara. Censo da Religião: um instrumento dispensável ou reciclável?. Religião \& Sociedade, v. 24, n. 2: p. 152-159, 2004.

MAGNANI, José Guilherme Cantor. O circuito neo-esotérico. In: TEIXEIRA, Faustino; MENEZES, Renata (Orgs.). As religioes no Brasil: Continuidades e rupturas. Petrópolis: Vozes, 2006.

MARIZ, Cecília; GRACINO Jr., Paulo. As igrejas pentecostais no censo de 2010. In: TEIXEIRA, Faustino; MENEZES, Renata (Orgs.). Religioes em movimento: o censo de 2010. Petrópolis: Vozes, 2013. No prelo.

MARIZ, Cecília; MACHADO, Maria das Dores C. Sincretismo e Trânsito Religioso: Uma Comparação Entre Pentecostais e Carismáticos. Comunicaçôes do ISER, v. 45, p. 24-34, 1994.

NERI, Marcelo (Org.). Novo Mapa das Religiōes. Rio de Janeiro: FGV Centro de Políticas Sociais, 2011. Disponível em: <http://www.cps.fgv.br/ cps/religiao/>. Acesso em: 17 maio 2013. 
PIERUCCI, Antônio Flávio; MARIANO, Ricardo. Sociologia da religião, uma sociologia da mudança. In: MARTINS, Carlos; SOUZA MARTINS, Heloísa (Orgs.). Horizontes das ciências sociais: Sociologia. São Paulo: ANPOCS, 2010. p. 279-301.

RODRIGUES, Denise dos Santos. Os "sem religião" e a crise do pertencimento institucional no Brasil: o caso fluminense. Tese (Doutorado em Ciências Sociais) - Universidade do Estado do Rio de Janeiro, Rio de Janeiro, 2009.

SILVA, Janine Targino da. Lideranças pentecostais femininas. Dissertação de Mestrado em Ciências Sociais. - PPCIS, Universidade do Estado do Rio de Janeiro, Rio de Janeiro, 2010.

SOUZA, Carlos Henrique Pereira de. Entre a capela e a catedral: tensões e reinvenções da identidade religiosa na experiência do protestantismo histórico atual. Dissertação (Mestrado em Ciências Sociais) - Universidade do Estado do Rio de Janeiro, Rio de Janeiro, 2013. 